\title{
Gender Dimension in Predictors of Students' Performance in MOCK-SSCE Practical and Theory Chemistry Examinations in Some Secondary Schools in Nigeria
}

\author{
Emmanuel E. Achor ${ }^{1, *}$, Seraphina M. Kurumeh ${ }^{1,2}$, Christopher A. Orokpo \\ ${ }^{1}$ Department of Curriculum \& Teaching, Benue State University, Makurdi-Nigeria \\ ${ }^{2}$ Science and Technical School Management Board, Benue State, Makurdi-Nigeria
}

\begin{abstract}
In this study the researchers used the results of students' alternative to practical knowledge of Chemistry and their tests of theoretical knowledge of Chemistry to predict students' performance in Chemistry in MOCK-SSCE. This study adopted the expost facto design. All the SS two Chemistry students constitute the population for this study. Out of 33 schools only 15 schools met the requirement for selection as a science secondary school. Eight of these schools with a science student population of 128 (Male $=64$; female $=64)$ were randomly selected and used for this study. The instruments used for this study were the students' alternative to test of practical knowledge of Chemistry (SATPKC) and the students' tests of theoretical knowledge of Chemistry (STTKC). These instruments were developed by the researchers and administered to the SS 2 science students. The reliabilities of the instruments were established during the pilot study using test - retest method. The reliability was calculated using Kuder Richardson (K-R21) and was found to be .94 for SATPKC and .89 for STTKC. The data for answering research questions were analyzed using the mean scores. Using multiple regression analysis for the hypotheses, the results show that male and as well female students' performance in a test of theoretical knowledge in Chemistry do not significantly predict their performance in MOCK-SSCE Chemistry theory examination. Male and female students' SATPKC score could not significantly predict their MOCK-SSCE mean practical scores. The overall relationship between SATPKC, MOCK-SSCE practical and MOCK-SSCE theory for male as well as female students were not significant. It was recommended that Principals of schools should ensure that both male and female science students are actively involved in practical work weekly as it will go a long way to enhance their performance during practical test and that efforts aimed at bridging the gaps between theory and practical performance of students in secondary school chemistry should not be gender discriminatory among others.
\end{abstract}

Keywords Practical chemistry, alternative to practical, Chemistry performance, Chemistry achievement, MOCK-SSCE, Benue State Examination Board, gender

\section{Introduction}

Laboratory experiments (activities) are characteristic features of science teaching at all levels of education (Adane \& Adams, 2011). They serve as indispensable parts (components) in this regard since origin of the use of laboratory methods in science teaching long time ago (Garnett, Garnett \& Hacking, 1995; Hofstein \& Lunetta, 2004; Hofstein \& Mamlok-Naaman, 2007; Borrmann, 2008; Fisher, Harrison, Hrnderson \& Holston, 1998). Nowadays, it is rare to find any science course without a substantial component of laboratory activity in teaching institutions. During such laboratory experiments, students are provided with specimens

* Corresponding author:

nuelachor@yahoo.com (Emmanuel E. Achor)

Published online at http://journal.sapub.org/edu

Copyright (C) 2012 Scientific \& Academic Publishing. All Rights Reserved or work guide (manual) and some sort of equipments which help them to investigate scientific problems in order to understand theories and principles of science subjects (Adane \& Adams, 2011). Students have a lot to benefit from practical which may include increasing students' interest and abilities in science subjects as well as their achievement in science (Bryant \& Edmunt, 1987; Emoyi, 2006; Pavesic, 2008). Demonstrations by instructors can also be used as an option to support theories and lectures given in class rooms in institutions without adequate facilities to let students do the experiments by themselves (Agbo \& Mankilik, 1999; McKee, 2007). However, as stated by Tobin (1990) and Ikeobi (2004), meaningful learning is possible from a given laboratory experiments if the students are given ample opportunities to operate equipments and materials that help them to construct their knowledge of phenomena and related scientific concepts. There are reports that emphasize teaching a science with the help of laboratory experiments 
to be more enjoyable and stimulating to students than teaching the same subject matter only through lecture (Hofstein, 2004; Teibo, 2001). Similar to other science subjects, teaching Chemistry is also supported by laboratory experiments (practical sessions) (Reid \& Shah, 2007). The original reason for development of chemistry laboratories (experiments) was the need to produce skilled technicians for industry and highly competent workers for research laboratories (Morrell, 1969). Chemistry practical classes (experiments) are believed to help students in understanding theories and chemical principles which are difficult or abstract. Moreover, they offer several opportunities to students. Some of these opportunities include handling chemicals safely and with confidence, gain hands-on experience in using instruments and apparatus, develop scientific thinking and enthusiasm to chemistry, develop basic manipulative and problem solving skills, gain opportunities to students as investigators of the experimental work, identify chemical hazards and learn to assess and control risks associated with chemicals (Lagowski, 2002; Pickering, 1987; Carnduff \& Reid, 2003; Ravishankar \& Ladage, 2009).

There are two extreme thoughts regarding the importance of Chemistry laboratory experiments. The first one is that in traditional approaches, little opportunity is given to the student initiatives or circumstance. In this approach, all the laboratory procedures are carefully listed in the provided manual, and frequently the student is simply asked to fill in a well planned report template. At the end of a laboratory session, students have no real opportunity of understanding or learning the process of doing Chemistry. This situation is similar to what obtains in alternative to practical in Nigeria especially in WAEC/SSCE. The second one is that a student is given an opportunity to engage in deep learning (Gunstone \& Champagne, 1990). This would provide an opportunity in identifying the main objectives of the work and in planning and executing it, of identifying the conceptual and practical difficulties encountered, recording and discussing the results and observations and of suggesting practical alterations and improvements (Teixeira-Dias, Pedrosa de Jesus, Neri de Souza \& Watts, 2005). The latter, thus, could result in a significant positive impact on a students' ability to learn both the desired practical skills and also the underlying theory (Akpa, 2005). How familiar students are to what is expected of them and what sex role stereo type they are attached to could influence how they perform in both practical and theoretical aspects of chemistry examination.

General observations indicate that students perform poorly in chemistry practical. Ministry of Education (2001) and WAEC Chief Examiner's Report (2002) attributed the poor performance especially in practical aspect of Chemistry to their non-familiarity with the use of simple laboratory equipment, imprecise statement, spelling errors, inadequate exposure to laboratory techniques, lack of observational skills, inability to determine mole ratio from stoichiometric equations, omission of units in calculated values, inability to write symbols properly and assign correct charges to ions, among others. In the theory paper, poor performance of students was also attributed to a number of reasons which include their inability to represent simple reaction by balanced equations, violation of the convention for IUPAC nomenclature, tendency to crowd their answers together, poor spellings, definitions and diagram, non-familiarity with some contents of the syllabus, lack of depth and precision in the responses to essay questions, inadequate understanding of the fundamental principles in Chemistry, inability to distinguish between physical and chemical properties and incompetence in basic Mathematics and other factors that affect students performance in Chemistry. Whether these differences identified could affect students' performance in practical and theory examinations in Chemistry especially along line of gender have not been fully determined. Again, whether students' performance in the tests of practical and theoretical knowledge of Chemistry could predict their performance in MOCK-SSCE practical and theory Chemistry examinations on the basis of gender have not been empirically determined.

Students write examinations in MOCK-SSCE and SSCE yearly. Such students' results in SSCE and MOCK-SSCE are often sent down in comprehensive form in the final grade. The scores of students in test of practical and theory aspects are not shown. However, in MOCK-SSCE conducted by the State, the raw scores of the two aspects of Chemistry could easily be obtained separately to allow for comparison of the students' performance in the two major aspects of Chemistry examinations. In MOCK-SSCE, students are tested in theory of practical (i.e. alternative to practical) knowledge instead of the real practical work. Could the results of students obtained in the test of practical and theoretical knowledge of Chemistry predict their performance in MOCK-SSCE on the basis of gender? It is against this background that the researchers undertake this study to find out if the students' performance in tests of practical and theoretical knowledge of Chemistry could predict their performance in MOCKSSCE on the basis of their gender.

There are indications at all levels of education in Nigeria that females are grossly underrepresented in terms of enrolment, participation and achievement in science, technology and Mathematics education (Okeke, 1990; Maduabum, 2006; Anaekwu \& Nnaka, 2006). The same studies clearly indicate the state of affairs at the secondary level of education in Nigeria that a greater proportion of males enrolled and achieved higher than their female counterparts. Elsewhere observations on the disparity in male-female performance in sciences exist (Ssempala, 2005; Hodson, 1999). Studies carried out by Tamir (1982) and Burns (1987) in Israel and New Zealand respectively, have also shown that male students outperformed their female counterparts in the physical sciences. The report of similar study conducted by Anderson (1987) indicated that in America, there were too few women in the sciences and related professions like Engineering and Technology.

Okeke (1990), reported that boys perform better than girls on physical science questions and high level questions (application, analysis and synthesis) whereas girls do as well as, 
or better than boys on questions in Biological sciences and lower level (knowledge, recall and comprehension) questions. Research study carried out by Mari (2001) focused mostly on the effect of gender factors on students' understanding of science process skills in science learning among junior secondary schools students in some eleven (11) selected junior secondary schools (classes $1-3$ ) from Zaria and Sabon Gari Local Government Areas of Kaduna State. The target was 330 students that were chosen through the stratified sampling method. The results show that: (1) the subjects possessed low understanding of science process skills. (2) The female students were significantly better in their understanding of science process skills than their male counterparts. (3) There was significant difference between the male and female students in their ability to solve problems requiring their understanding of the process skills as pre-requisites for achievement in Biology.

The findings on gender as reviewed focused on several variables affecting performance of students in science. None has looked specifically at the practical styles the students have been exposed to, in relation to students' performance in chemistry and on the basis of their gender. Therefore, it is also of interest to find out if the relationship changes with sex of students in MOCK-SSCE Examination in Ogbadibo Local Government Area of Benue State.

\section{Research Questions}

The following research question guided the study:

What is the pattern of SS II male and female students' mean performance in tests of practical and theoretical knowledge of Chemistry as well as their MOCK-SSCE practical and theory Chemistry examinations?

\section{Hypotheses}

The following null hypotheses were formulated at 0.05 alpha level of significance and guided the study.

1. SS II male students' mean performance in a test of practical knowledge in Chemistry does not significantly predict their performance in MOCK-SSCE Chemistry practical examination.

2. SS II female students' performance in a test of practical knowledge in Chemistry does not significantly predict their performance in MOCK-SSCE Chemistry practical examination.

3. SS II male students' mean performance in a test of theoretical knowledge in Chemistry does not significantly predict their performance in MOCK-SSCE Chemistry practical examination.

4. SS II female students' mean performance in a test of theoretical knowledge in Chemistry does not significantly predict their performance in MOCK-SSCE Chemistry practical examination.

\section{Materials and Methods}

This study has adopted the expost facto design. This is due to the fact that the researchers intend to identify the level which one variable can predict a second related variable and the respondents were not subjected to treatment but simply after what they know already. In this study; the researchers used the results of students' alternative to practical knowledge of Chemistry and their tests of theoretical knowledge of Chemistry to predict students' performance in Chemistry in MOCK-SSCE.

The population of the study consists of all senior secondary school 2 science students from Government grant aided schools and privately owned schools that offer Chemistry in WAEC and NECO SSCE. SS 2 Chemistry students were used for this study. The criteria for selecting the population of the study were that the schools must have presented students for MOCK-SSCE in Chemistry for at least four years. MOCK-SSCE Examination is written in Benue State Nigeria by only SS 2 students.

There are 33 schools in the Local Government Area with a total population of 374 science students. Out of these 33 schools only 15 schools met the requirement for selection as a science secondary school. Eight of these schools with a science student population of 128 were randomly selected and used for this study. The criteria used for the selection of these schools include the fact that three of the schools must be from each of the three districts that constitute the study area, (2) the schools must offer all the three science subjects (Biology, Chemistry and Physics), and (3) the schools must have also presented students for SSCE for at least four years. It is on these bases that the eight schools were selected. In this study, 128 students (64 males and 64 females), that is, about $65 \%$ of the total population of 197 were used and have equal representation in the sampled schools. Proportionate random sampling technique was adopted to select the male and female students from the different schools. This is because this method of sampling gives each member of the population a fair and equal chance of being chosen.

The instruments used for this study were the Students' Alternative to Test of Practical Knowledge of Chemistry (SATPKC) and the Students' Tests of Theoretical Knowledge of Chemistry (STTKC). These instruments were developed by the researchers and administered to the SS 2 science students. Section A of SATPKC contains personal data of the respondents. Section B consists of 20 questions on students' alternative to tests of practical knowledge of Chemistry (SATPKC). Each question has four options lettered A - D. The respondents were asked to choose the correct option and circle the letter that bears the correct option.

Section B of STTKC also contains 20 items while section A contains the personal data. Each item has four options lettered $\mathrm{A}-\mathrm{D}$. The respondents were asked to choose the correct option and circle the letter that bears the correct option.

MOCK-SSCE Examination is conducted in Benue State in all schools prior to May/June SSCE. The examination which is conducted centrally by Benue State Examination Board in Nigeria cuts across all subjects offered in the schools including Chemistry. The questions for this public and all important examination are generated during item writing 
workshops often organized by Benue State Examinations Board in conjunction with Teaching Service Board and Ministry of Education Headquarters, Makurdi. The questions so generated are kept in the questions Bank. Various subject teachers are used for the generation of these questions. The questions, SATPKC and STTKC are set, taking into cognizance the bloom taxonomy of education and in accordance with the syllabuses of WAEC and NECO examination bodies.

To ensure the validity of the instruments, the following measures were employed. It was ensured that questions were not ambiguous, double barrelled statements were avoided. Content and face validity were carried out by experts in science education with Table of specification attached. Specifically, three science education experts and one in measurement and evaluation did the validation.

The reliabilities of the instruments were established during the pilot study using test - retest method. It was administered in a school outside those sampled for the main study to 20 students. The reliability was calculated using Kuder Richardson $\left(\mathrm{K}-\mathrm{R}_{21}\right)$ and was found to be .94 for SATPKC and .89 for STTKC. These values were considered good enough to guarantee the use of the instruments.

With the permission from the school principals and the assistance of the science teachers, the questions on the two aspects of Chemistry (i.e. theory and practical) were administered by the researcher on the sampled students. The two sets of scores from students' alternative to tests of practical knowledge of Chemistry and students' tests of theoretical knowledge of Chemistry were collected and recorded. The performance scores of the students in MOCK-SSCE of the sampled students in these two areas were collated.

The scores obtained from the respondents on the tests on alternative to practical knowledge of Chemistry and theoretical knowledge of Chemistry were used to predict their performance in MOCK-SSCE collected from Benue State Examinations Board, Makurdi. The data answering research questions were analyzed using the mean statistics. Multiple regression was used for analysis to determine the extent to which the dependent variable were predicted. Thus all the hypotheses were tested using the result from the multiple regression.

\section{Results}

Presentation of results in this study is according to research question and hypotheses.

\subsection{Research Question One}

What is the pattern of male and female students' mean performance in test of practical and theoretical knowledge of Chemistry as well as their MOCK-SSCE practical and theory Chemistry examinations?

Table 1 reveals that mean score for males and females are 8.7812, 7.7031 for SATPKC; 8.0156, 7.4219 for STTKC; $11.1408,10.5625$ for MOCK practical; 7.3906, 7.4375 for
MOCK theory respectively. Thus consistently the males outperformed the females except in MOCK-SSCE theory examination where there appear to be a tie. However, the standard deviation for the same examination (MOCK-SSCE theory) shows that the males had a better spread out scores compared to the females.

Table 1. Mean and Standard deviation for SS II male and female students' performance in SATPKC, STTKC, MOCK-SSCE practical and theory Chemistry examinations

\begin{tabular}{ccccc}
\hline Examinations & Gender & Cases, N & Mean & Standard Dev. \\
\hline SATPKC & Male & 64 & 8.7812 & 2.08143 \\
& Female & 64 & 7.7031 & 1.62011 \\
STTKC & Male & 64 & 8.0156 & 1.9206 \\
& Female & 64 & 7.4219 & 1.59169 \\
MOCK Pract. & Male & 64 & 11.1408 & 2.51262 \\
& Female & 64 & 10.5625 & 2.22450 \\
MOCK Theory & Male & 64 & 7.3906 & 2.40117 \\
& Female & 64 & 7.4375 & 2.00693 \\
\hline
\end{tabular}

\subsection{Hypotheses}

Hypothesis 1: SS II male students' mean performance in a test of practical knowledge in Chemistry does not significantly predict their performance in MOCK-SSCE Chemistry practical examination.

Table 2. Predictive values of mean MOCK Practical and MOCK Theory scores on SATPKC for male students from Multiple Regression analysis

\begin{tabular}{cccc}
\hline Exam & Beta value & $\mathrm{T}$ & Sig. \\
\hline Constant & - & 5.434 & .000 \\
MOCK Practical & .039 & .296 & .768 \\
MOCK Theory & -.051 & -.395 & .694 \\
\hline
\end{tabular}

*Dependent variable: SATPKC

*Selecting only cases for which gender $=$ male

Table 2 shows that a $t$ value of .296 is only significant at .768 which is higher than .05 (or $95 \%$ confidence level). This implies that male mean score in SATPKC could not significantly predict their MOCK-SSCE mean practical scores. The null hypothesis is therefore retained. Secondly, MOCK practical only contributed 3.9\% (i.e. .039) of the total value.

Hypothesis 2: SS II male students' mean performance in a test of theoretical knowledge in Chemistry does not significantly predict their performance in MOCK-SSCE Chemistry practical examination.

Table 3. ANOVA of relationship between mean MOCK Practical, MOCK Theory and SATPKC scores of male students

\begin{tabular}{cccccc}
\hline & Sum of Squares & Df & Mean Square & F & Sig. \\
\hline Regression & 1.335 & 2 & .668 & .150 & .861 \\
Residual & 271.602 & 61 & 4.452 & & \\
Total & 272.938 & 64 & & & \\
\hline
\end{tabular}

*Predictors: Constant), MOCK Theory, MOCK Practical

*Dependent variable: SATPKC

*Selecting only cases for which gender $=$ male

$* \mathrm{R}^{2}=.004$

With reference to Table 3 , a t value of -.395 is only significant at .694 which is higher than .05 . Therefore male SATPKC mean score could not significantly predict their MOCK-SSCE mean score. It could only contribute -.051 
$(-5.1 \%)$ to the total value. Table 9 equally reveals that the overall relationship between SATPKC, MOCK-SSCE practical and MOCK-SSCE theory mean male score is not significant, $\mathrm{F}_{2,64}=.150, \mathrm{p}>.05$.

Hypothesis 3: SS II female students' performance in a test practical knowledge of Chemistry does not significantly predict their performance in MOCK-SSCE Chemistry practical examination.

Table 4 reveals that with the $t$ value of .593 which is only significant at .555 , it means that Female mean score in STTKC could not significantly predict their mean MOCKSSCE practical examination scores. It only accounted for only $7.6 \%$ (i.e. .076) of the total value.

Table 4. Predictive values of mean MOCK Practical and MOCK Theory scores on SATPKC for female students from Multiple Regression analysis

\begin{tabular}{cccc}
\hline Exam & Beta value & $\mathrm{T}$ & Sig. \\
\hline Constant & - & 5.652 & .000 \\
MOCK Practical & .076 & .593 & .555 \\
MOCK Theory & .032 & .249 & .804 \\
\hline
\end{tabular}

*Dependent variable: STTKC

*Selecting only cases for which gender $=$ female

Hypothesis 4: SS II female students' mean performance in a test of theoretical knowledge in Chemistry does not significantly predict their performance in MOCK-SSCE Chemistry practical examination.

Again Table 4 reveals that with a $t$ value of .249 which is only significant at .804, it implies that female mean STTKC score could not significantly predict their mean MOCKSSCE theory scores at .05 level of significance. Similarly, the overall relationship between STTKC, MOCK-SSCE practical and MOCK-SSCE theory for female mean scores is not significant as pointed out in Table $5, \mathrm{~F}_{2,63}=.227, \mathrm{p}>.05$.

Table 5. ANOVA of relationship between mean MOCK Practical, MOCK Theory and STTKC scores of female students

\begin{tabular}{cccccc}
\hline & Sum of Squares & Df & Mean Square & F & Sig. \\
\hline Regression & 1.335 & 2 & .589 & .227 & .798 \\
Residual & 271.602 & 61 & 2.597 & & \\
Total & 272.938 & 63 & & & \\
\hline
\end{tabular}

*Predictors: Constant), MOCK Theory, MOCK Practical

*Dependent variable: STTCK

*Selecting only cases for which gender $=$ female

$* \mathrm{R}^{2}=.007$

\section{Discussion of Findings}

The finding of this study which shows that SS II male students' performance in a test of practical knowledge in Chemistry could not significantly predict their performance in MOCK-SSCE Chemistry practical examinations is in disagreement with Mari (2001) who confirmed that male students' performance in a test of practical Biology enhanced male students' performance in NECO/SSCE Biology practical. Akpa (2005) made similar finding. It also contradicts Okeke $(1990,2002)$ who affirmed that male students' performance in a test of practical aspect of Physics influence their practical performance in WASSCE Physics in 1989. The result from the present study departed remarkably from some previous findings probably because of the way examinations are conducted/supervised in schools. Most schools see examination as a do or die affairs and so go all out to ensure pass at all cost even when they do not have the ability. Such examinations include all external ones like WAEC/SSCE, NECO/SSCE and MOCK-SSCE. Since Mock-SSCE is one of the variables in the present study, one may not be surprised at the contradictory report. Most probably examination malpractices may have been condoned in some resulting in unrelated scores from the different examinations.

Another finding in this study is that male students' performance in a test of theoretical knowledge in Chemistry does not significantly predict their performance in MOCKSSCE Chemistry practical examinations. This finding disagrees with Idoko (2005) that male students' performance in practical work enhances their performance in practical science examinations. It also contradicts Usman (2000) who found that male students' performance in a test of practical activities significantly predict their performance in practical activities when exposed to NISTEP mode of teaching. This finding is also in line with Idoko (2005) who affirmed that theoretical knowledge in science does not significantly influence students' performance in practical aspect of science as well as that of Emoyi (2006) who had similar finding in physics. Also, in disagreement with this finding, is the work of Amoo (2000) who found that theoretical knowledge of science enhances students' performance in the practical aspect of science. However, the last two works cited did not lay emphasis on gender. Also, when practical are not handled the way it ought to be, it is not likely that performance it will correlate positively with the performance in the theoretical aspect. Another result from the study shows that female students' performance in a test of theoretical knowledge in Chemistry does not significantly predict their performance in MOCK-SSCE Chemistry practical examination. This finding disagrees with Asoegwu (2008) who found that female students' performance in a test of practical knowledge in Biology predicted their performance in NECO Biology practical. Also, the finding contradicts that of Usman (2000) who found that female students' performance in practical aspect of Biology internal examination enhanced their performance in external examinations.

Another finding in this study shows that SS II female students' performance in a test of theoretical knowledge in Chemistry could not significantly predict their performance in MOCK-SSCE Chemistry practical examination. This finding disagrees with Mari (2001) who found that female student's performance in a test of theoretical knowledge in Physics significantly predicted their performance in MOCK-SSCE practical Physics. Also, this finding contradicted Okebukola (1997) who found that female students' performance in a test of theoretical knowledge in Agricultural Science do significantly predict their performance in Agricultural Science theory in WASSCE 1999. 


\section{Conclusions and Recommendations}

It can be concluded from this study that irrespective of gender, students score in test of practical and theoretical knowledge of chemistry could not predict their performance in MOCK-SSCE theory and practical examinations. Based on the findings of this research, the following recommendations were made.

The Principals of schools should ensure that both male and female science students are actively involved in practical works weekly giving everybody opportunity to participate irrespective of gender. This will go a long way to enhance their knowledge during practical.

Government should provide educational facilities and learning materials especially laboratory equipment to meet the needs of students during their study in theory and practical science particularly in Chemistry. Since this places students at a level to acquire both scientific skills and gain familiarity with the equipments, a particular sex should not have access more than the other as the knowledge gained during this stage is considered foundational.

\section{REFERENCES}

[1] Adams, C. S, 1942, the importance of laboratory work in general chemistry at the college level. J. Chem. Educ. 19: 266.

[2] Adane, L. and Admas, A., 2011, Relevance and safety of Chemistry laboratory experiments from students' perspective: a case study at Jimma University, southwestern Ethiopia. Educational Research, 2(12), 1749-1758.

[3] Agbo. F. A. and Mankilik, M, 1999. The evaluation of practical testing skills in SSCE examinations. Proceedings of the $40^{\text {th }}$ conference of Science Teachers Association of Nigeria. Ibadan: Heinemann, Education Book Nigeria.

[4] Akpa. U.N. 2005, Effects of practical knowledge of Biology as predictors of students' performance in theoretical aspect of Biology in selected senior secondary schools in Nsukka Local Government Area of Enugu State. Unpublished M.ED dissertation University of Nigeria, Nsukka.

[5] Anaedwe. M.C. and Nnaka, C.V. 2006, Students' enrolment and achievement in STM at Senior School Certificate Examination. Implication for available and utilization of instructional resources. Proceedings of $47^{\text {th }}$ Annual Conference of STAN held at Calabar.

[6] Andam. A. B, 2003, African women's Scientists. Why so few? Paper presented at the African Woman in Science and Engineering Workshop. Nairobi, Kenya.

[7] Anderson, L.W, 2005, Objectives, evaluation and the improvement ineducation. Studies in Eeducational Evaluation, $4(2), 16-24$.

[8] Asoegwu, A.O. (2008). The need for Gender Equity in Nigerian Science, Technology and Industrialization. Paper presented in the conference of national Association of Women Academics (NAWACS). Uniport Chapter, March 4.
[9] Borrmann, T, 2008, Laboratory education in New Zealand. Eurasia J. Math. Sci. Technol. Educ. 4: 327-335.

[10] Bryant, R.J,\& Edmunt, A.M, 1987, They like lab-centered science. Sci. Teacher. 54: 42-45.

[11] Burns, J, 2001, Encouraging girls and women in science: Getting going in willington, New Zealand. In Daniels, J. 2. \& Khale, J.B. (Eds). Contributions to the 45 GASAT conferences: GASAT 4(2) $266-273$.

[12] Carnduff, J. and Reid, N, 2003, Enhancing undergraduate chemistry laboratories, pre-laboratory and post-laboratory exercises, examples and advice. Education Department, Royal Society of Chemistry, Burlington House, Piccadilly, London.

[13] Emoyi, P.E., 2006, Students' performance in tests of practical and theoretical knowledge in Physics as indicators of their performance in WASSCE Physics in Iseyin Local Government Area of Oyo State. Unpublished ME.D Dissertation.

[14] Fisher, D, Harrison, A, Henderson, D, and Holstein, A, 1998), Laboratory learning environments and practical tasks in senior secondary science classes. Res. Sci. Educ. 28: $353-363$

[15] Garnett, P.J. Garnett, P.J. and Hacking, M.W, 1995, Refocusing the Chemistry lab: A case for laboratory-based investigations. Australian Sci. Teachers J. 41:26-32.

[16] Gunstone, R.F. and Champagne, A.B, 1990, Promoting conceptual change in the laboratory. In E. Hegarty-Hazel (Ed.). The student laboratory and the science curriculum (London: Routledge).

[17] Hofstein, A, 2004, The laboratory in Chemistry Education: Thirty years of experience with developments, implementation, and research. Chem. Educ. Res.Pract. 5: 247-264.

[18] Hofstein, A.and Lunetta, V.N, 2004, The laboratory in science education: Foundationfor 21st century. SCi. Educ. 88: 28-54.

[19] Hofstein, A. and Mamlok-Naaman, R, 2007, The laboratory in science education: The state of the art. Chem. Educ. Res. Pract. 8: 105-107.

[20] Hodson, A, 1999, Relevant Physics for everyone: Teaching societal topics in introductory Physics: In Kalalinietal (Ed), International conference on science education for the $21^{\text {st }}$ century.

[21] Idoko, J.S, 2005, The relationship between SS II students' performance and their attitudes to science practicals in Makurdi Metropolis. Unpublished MED Dissertation.

[22] Ikeobi, I, 2004, Identification and teaching of different concepts in Chemistry. STAN Bulletin, 11(2), 3 - 5.

[23] Johnstone, A.H. and Letton, K.M, 1988, Is practical work practicable?, J. College Sci. Teach. 18: 190-92.

[24] Lagowski J.J, 2002, The role of the laboratory in chemical education. Retrieved from http://www.utexas.edu/research/chemed/lagowski/jjl_beijing _02.pdf (Accessed on 29 Sep, 2011).

[25] Maduabum, M. A, 1999, Toward constructive science education for the Nigeria children.In B.C.

[26] Maduabum, M.A, 2003, Gender differences in educational 
participation and performance in Science, Technology and Mathematics: A Nigerian perspective. International Journal of Woman's Students' 3(6), $217-224$

[27] Maduabum, M.A, 2005, Sex difference in attitude towards science achievement in science in Nigeria. An analysis of 12 years of research. Journal of Technical and Science Education, $2(1 \& 2), 63-71$.

[28] Maduabum, M.A, 2006, Strategies of improving the access of girls and women in Science, Technology and Mathematics (STM). University Education in Nigeria. Ebonyi Journal of Science Education, 1(1), 1- 12.

[29] Madukwe, E A, 1999, Stoichiometry calculations in trimetric analysis and preparation of some solutions for ordinary practical Chemistry. Implications to teaching and learning. STAN Journal, 25(2), $32-35$.

[30] Mari, J.S, 2001, The effect of science process based instruction on formal reasoning. Unpublished $\mathrm{PhD}$ Thesis, Department of Education. A.B.U. Zaria.

[31] McKee, E, Williamson, VM, and Ruebush, L.E, 2007, Effects of a demonstration laboratory on student learning. J. Sci. Educ. Technol. 16: 395-400.

[32] Ministry of Education, 2001, Benue State examination report. State Official gadget

[33] Morrell, J.B, 1969, Practical Chemistry at the University of Edinburgh, 1799-1843, $A M B I X$. 26: 66-80

[34] Okebukola, P.A.O.(2001). Students' performance in practical Chemistry: A study of some related factors. Journal of Research in Science Teaching, 24 (2), $119-126$.

[35] Okeke, E. A.C, 2002, Gender, science and technology for Africa. A challenge for education. The 2000 Rama mental lecture. Radellife College.

[36] Pavesic, B.J, 2008, Science achievement, gender differences, and experimental work in classes in Slovenia as evident in TIMSS studies. Studies In Educ. Evaluat. 34: 94-104.

[37] Reid, N. and Shah, I, 2007, The role of laboratory work in University Chemistry. Chem. Educ. Res. Pract. 8: 172-185.
[38] Pickering, M, 1987, What goes on in students' heads in laboratory? J. Chem. Educ. 64: 521-523

[39] Polles, J.S, 2006), The Chemistry teaching laboratory: The student perspective. PhD thesis, Purdue University, Indiana, USA.

[40] Ravishankar, L, and Ladage, S, 2009, Laboratory Courses in Organic Chemistry: A Case Study. Chem. Educ. in the ICT Age. 325-332.

[41] Ssempala, F, 2005, Gender differences in performance of Chemistry practical skills among senior six students in Kampala District. PhD thesis. Boca Raton, Florida, USA Dissertation.com)

[42] Tamir, P, 1999, The relationship among cognitive preference School Environment Teachers curricula Bias, curriculum and subject matter. American Education Research Journal, 12 (3), $235-64$.

[43] Teibo, B.O, 2001, Using criterion referenced tests in diagnosing pupils' problems in learning the mole concept in Chemistry. Journal of Science Teachers Association of Nigeria. $22(1), 85-92$.

[44] Teixeira-Dias, .J.J.C, Pedrosa de Jesus, M. H, Neri de Souza, F. and Watts, M, 2005, Teaching for quality learning in Chemistry. Intl. J. Sci. Educ. 27: 1123-1137.

[45] Tobin, K.G, 1990, Research on science laboratory activities: In pursuit of better questions and answers to improve learning. School Sci. Math. 90: 403-418.

[46] Usman, I. A, 2000, The relationship between students' performance in practical activities and their academic achievements in integrated science using NISTEP mode of teaching. Unpublished M ED Dissertation A.B.U. Zaria.

[47] WAEC, 1999, Chief Examiners Report. Lagos: West African Examinations Counsel

[48] WAEC, 2002, Feb. 23 -27, Report on May/June 2003.2006 and SSCE to the $4^{\text {th }}$ meeting of National Council on Education (NCE), Kastina Nigeria. 